MOD MEKKAWI

\title{
The ARL Library Index as a Decision-Making Tool
}

In May of 1980 the Association of Research Libraries (ARL) adopted new criteria for membership in the association based, in large part, on what is known as the ARL Library Index. ${ }^{1}$ This index is derived from a model containing ten categories, or variables, which characterize library size.

While the Library Index model was developed as a measure of an institution's overall standing relative to the ARL membership, this author has found it to be useful, if properly employed, as a decision-making tool in short-term planning, programming, and budgeting in those operations affecting library size. This article describes the procedure for this application of the index.

\section{WhAT IS THE LIBRARY INDEX?}

Until 1980, ARL Statistics described the size and rank of ARL member institutions separately in terms of holdings, expenditures, staffing, and interlibrary loan activity. While the institutions could be compared on these variables, one at a time, there was no summary measure of an institution's overall ranking in the association. The ARL model was designed to provide such a summary characterization.

The model is as follows:

$$
\Sigma F S C_{i}\left(\log k_{i}-\log K_{i}\right) / \text { s.d. } K_{i}
$$

where, in a given year:

$F S C_{i}=$ Factor score coefficient of variable $i$;

$k_{i} \quad=$ Value of variable $i$ for the study institution;

$K_{i} \quad=$ Mean of variable $i$

s.d. $K_{i}=$ Standard deviation of variable $i$.

The ten variables included in the model are defined as:

1. Volumes held, excluding microforms and government documents;

2. Volumes added (gross), excluding mi-

Mod Mekkawi is architecture and planning librarian, Howard University, Washington, D.C. croforms and government documents;

3. Microforms held, including microfilm reels, microcards, microprints sheets, microfiches;

4. Current serials received, including periodicals;

5. Expenditures for library materials, including books and serials;

6. Expenditures for binding;

7. Expenditures for salaries and wages, including student assistants' wages, but omitting fringe benefits;

8. Other operating expenditures; and

9. Number of FTE professional staff;

\section{Number of FTE nonprofessional} staff.

Thus for XYZ university library (a hypothetical institution), the index score will be calculated by substitution of the variables in the model with their corresponding values for this library. Using the 1979/80 ARL model, we calculate XYZ's index as shown in table 1. As it turns out, some of the calculated component scores are negative, which indicates areas in need of improvement if XYZ institution wishes to score higher in ARL.

Given certain characteristics of the ARL model and the current conditions at XYZ, how can this institution achieve a certain improved index score most economically? Note that in $1979 / 80$, the scores of the ARL members ranged from a low of -1.93 (Oklahoma State) to a high of +3.00 (Harvard), with -.38 for the university median.

\section{Management Application OF THE ARL MODEL}

The library administration will set a goal to achieve a certain index score within a given time framework-for instance, one year. Given the library's current component values, its costs of increasing each independent variable (book, serial, microform) by one unit, the costs of increasing the depen- 
TABLE 1

Procedure for Calculating the Library Index, XYZ University Library, 1979/80

\begin{tabular}{|c|c|c|c|c|c|c|c|c|}
\hline $\begin{array}{l}\text { Component } \\
\text { Variable }\end{array}$ & $F S C_{i}$ & & $k_{i}$ & $K_{i}$ & & $\begin{array}{l}\text { s.d. } \\
K_{i}\end{array}$ & & $\begin{array}{c}\text { Component } \\
\text { Score }\end{array}$ \\
\hline 1. VOLHELD & .12108 & $(\log$ & 11163 & $-6.2916)$ & $T$ & .2172 & $=$ & -0.135897 \\
\hline 2. VOL & & & & & i & & & \\
\hline 3. MIC FORM & .075 & $\log$ & 11650 & -6.0950 & i & .17 & $=$ & -0.012200 \\
\hline 4. CT SEI & .12253 & $(\log$ & 131 & -4.3432 & i & .2341 & $=$ & -0.117283 \\
\hline 5. MAT & .1255 & $\log$ & 18943 & -6.23 & i & .16 & $=$ & 0.03 \\
\hline 6. BIND & .11266 & $(\log$ & 34132 & -5.0480 & $i$ & .24 & $=$ & -0.234350 \\
\hline ARIES & .12581 & $(\log$ & 36093 & -6 & $i$ & .21 & $=$ & 0.0 \\
\hline 8. OPER EXPEND & .10592 & $(\log$ & 625014 & $-5.6773)$ & i & .26 & $=$ & 0.047670 \\
\hline 9. PROF STAFF & .123 & $(\log$ & 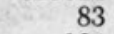 & & I & .19 & $=$ & 0.057079 \\
\hline 10. NONPROF & 12970 & $(\log$ & 124 & $-2.1512)$ & I & .2046 & $=$ & -0.031902 \\
\hline Total score ( & Index) & & & & & & & -0.385493 \\
\hline
\end{tabular}

dent variables (materials expenditures, binding, salaries and wages, other operating expenditures) caused by one unit increase in the dependent variables, and the weight of the dependent and independent variables in the ARL model, one can apply linear programming principles to find the best use of the library's resources.

Because this problem involves not only product mixing (books/serials/microforms), but also changes in the dependent components as the products are increased in certain ratios and quantities, formal linear programming techniques can be unnecessarily complex. The author has therefore worked out a shortcut procedure that may well yield the optimization effect sought in a formal linear programming solution.

Before looking at the procedure, let us state the major requirements of the problem:

1. There must be an objective the library wants to achieve. Obviously, its major objective, in terms of ARL standing, is to maximize the total contribution of the components in the ARL model. The component contributions, or scores, add up to the Library Index.

2. There must be alternative courses of action, one of which will achieve the above objective. In what ratio should the library increase its book/serial resources-1:1? 3:1? $0: 1$ ? Some other ratio?

3. Dollar resources are limited. One serial may cost twice as much as one book. Consequently, the more money that is spent on serials, the less there will be to spend on additional books.

4. The ratio of book:serial and the amount of books and/or serials additions needed to achieve the objective (a target
ARL score) depend (beside costs and proportion of serial subscriptions going into the collection as volumes added) on the component score coefficients, or weights, in the ARL Library Index model.

\section{Procedure}

The computational routine is an iterative process. In working toward the target score, the routine is repeated over and over, in a systematic pattern, until the preestablished score value has been reached.

Of the three independent variables in the model-books, current serials received, and microforms-we shall use, to simplify the problem, two "products" only, namely books and serials. In what ratio should these variables be increased?

Assume lower and upper limits of 0 and 9 for either element in the relation. That is, in the extreme cases, the book:serial ratio can be $0: 9$ or $9: 0$. There are fifty-seven alternative exclusive ratio combinations: $0: 1,1: 0$, $1: 1,1: 2,1: 3$, etc.

Assume also that all new serial additions are bound and added to the collection, and that one serial title produces one bound volume on the average. Thus, increasing books and serials by one unit each (1:1 ratio) will increase volumes added and volumes held by two units each. Similarly, a 4:1 ratio will increase volumes added and volumes held by five units each.

At the same time, expenditures for materials, binding, total salaries, other operating items, and the quantity of manpower needed to carry the additional work loads, are all increased by appropriate amounts for each one serial or monographic addition. These amounts are displayed in table $2 .^{2}$ 
TABLE 2

InPUt Data Caused by AdDition OF ONE Monographic OR SERIAL UnIT TO THE COLLECTION

\begin{tabular}{llc}
\hline $\begin{array}{l}\text { Component } \\
\text { Variable }\end{array}$ & $\begin{array}{c}\text { Item } \\
\text { Added }\end{array}$ & $\begin{array}{c}\text { Additional Unit } \\
\text { Cost per Item }\end{array}$ \\
\hline MAT EXPEND & Book & $\$ 25.0$ \\
BINDING & Serial & 50.0 \\
SALARIES & Book & 0.0 \\
PROF STAFF & Serial & 7.0 \\
& Book & 20.0 \\
NONPROF & Serial & 23.0 \\
& Book & .00059 manyear \\
& Serial & .00059 manyear \\
& Book & .00073 manyear \\
& Serial & .00093 manyear \\
\hline
\end{tabular}

Note: The personnel and salaries data are based on (1) known work-load factors for library operations and (2) estimated annual salaries and wages of $\$ 20,000$ and $\$ 12,000$ for professionals and nonprofessionals, respectively.

Before we begin the computations, we must adjust the basic data for XYZ by adding initially to its VOLHELD a quantity equal to the number of volumes added in $1979 / 80$. The assumption here is that $\mathrm{XYZ}$ will add to its collection in the projected year, books and serials in the proportions and quantities reported in the previous year. All other additions, needed to improve the index score, will be over and above the initial increments. The rate of serial binding is again assumed to be 100 percent. Thus, for XYZ, the value of volumes at the start of the computational routine is $1174396(1116396+58000)$.

Using the adjusted statistics and the input data from table 2 , the PL/1 program given in appendix 1 develops solutions to this problem. For each of the eleven ARL target scores, ranging from 0 to 1.0 , the program produced fifty-seven tables, a sample of which is given in table 3 . The optimal solution for each target score is that that corresponds to the lowest amount of total additional expenditures shown at the foot of each table. The book:serial ratio can be easily determined from the input data printed above the table, where the second item represents volumes added (monographs plus serials), and the third item units of serials added in each loop. Hence, the book:serial ratio in table 3 is $1: 3$.

For XYZ library, the optimal book:serial ratio is $0: 1$ for each of the eleven alternative score targets: that is, if a certain target score were to be achieved most economically, all additional funds would have to be allocated to increasing the number of current serials received, while book additions remained at the previous level.

What if the proportion of additional serials that are bound into volumes was less than 100 percent? Table 4 shows that the book:serial ratio of $0: 1$ remains the optimal product mix at every rate of binding except zero, that is, when none of the additional serial titles is bound at year's end. At the same time, the cost of achieving the given target score increased as the rate of binding dropped from one to zero. Except for binding expenditures, which obviously decreased as the proportion of serials sent to bindery decreased, all the other expenditures increased as more serials had to be added to reach the same score. This observation is quite instructive. It indicates that a certain score can be reached less expensively when most, if not all, of the current se-

TABLE 3

Sample Resource Allocation Table for Improved Index Score $\left(\mathrm{LI}=0.100000 \quad\right.$ DATA $\left.=\begin{array}{llllllll}4 & 4 & 3 & 175 & 20 & 21\end{array}\right)$

\begin{tabular}{lrrrr}
\hline \hline Component & Current & $\begin{array}{c}\text { Value } \\
\text { Target }\end{array}$ & Increase & \multicolumn{1}{c}{$\begin{array}{c}\text { Target } \\
\text { Score }\end{array}$} \\
\hline VOLHELD & 1174396 & 1184676 & 10280 & -0.121520 \\
VOLADDED & 57902 & 68182 & 10280 & -0.004434 \\
MICROFORMS & 1165076 & 1165076 & 0 & -0.012201 \\
CT SERIALS & 13156 & 20866 & 7710 & -0.012431 \\
MAT EXPEND & 1894321 & 2344071 & 449750 & 0.104875 \\
BINDING & 34132 & 88102 & 53970 & -0.046891 \\
TOTAL SALARY & 3609365 & 3839637 & 230272 & 0.069869 \\
OPER EXPEND & 625014 & 676414 & 51400 & 0.061470 \\
PROF STAFF & 83 & 89 & 6 & 0.076295 \\
NONPROF & 124 & 133 & 9 & -0.015017 \\
TOTAL & & & & 0.100015 \\
\hline
\end{tabular}

Total Additional Expenditures $=785392$. Binding Rate $=1.0$ 
rials received are bound and added as volumes to the collection. This is less costly than subscribing to an increasingly larger number of titles and discarding a large proportion of the hard copies at year's end in favor of (1) microfilm or (2) straight elimination as a limited number (just over 7,000 ) of currently published serials are available on microfilm.

\section{Conclusion}

It has been shown how the ARL Library Index model can be used in a large-scale library operation to:

1. Determine alternatives in the allocation of additional funds and the total amount needed in each case to reach a certain improved ARL score;

2. Determine which combination of various library materials will produce the expected outcome less expensively;

3. Identify the concomitant increases in staffing, salaries, binding, and other operating costs; and

4. Identify the trade-offs between the optimal solution and less efficient alternate solutions to achieve the established goal.

This information is especially valuable in a planning-budgeting process which uses Zero Base Budgeting (ZBB) techniques.

Obviously, the selection of a course of action is not altogether quantitative. The decision is often affected by issues that are not amenable to quantification. These issues relate to the overall objectives of the institution, its policy, or social values. Whereas the median ARL library spends about 55 percent of its materials budget on serials (with 80 percent for the ARL university high and 20 percent for the university low), a non-researchoriented institution need not, and indeed should not, follow the ARL pattern, which tends to focus on current serials acquisition. Similarly, an academic library that trails far behind comparable institutions in terms of monographic holdings would adopt a nonoptimal solution where the higher costs of developing resources and achieving a certain measure of library size will be justified by the requirements of filling gaps in the book and microform collections.

A nonoptimal solution should also be favored where space is a scarce resource; or where the flow of funds for library materials is erratic from year to year, for serial sub-

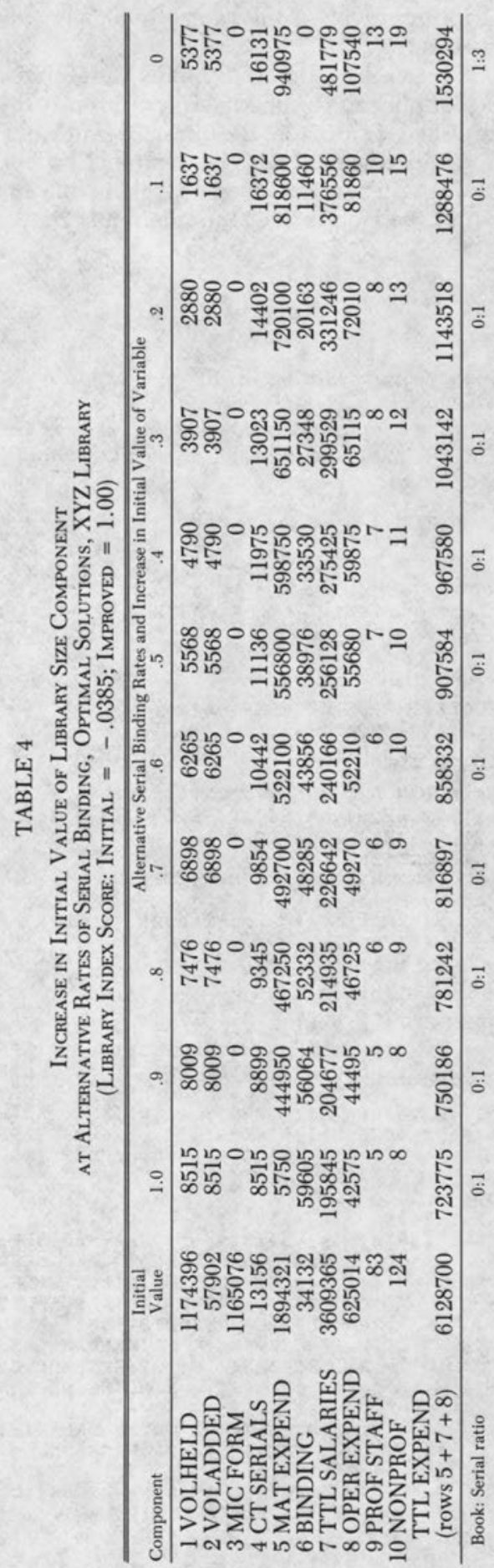


scriptions involve long-range financial commitment.

Nevertheless, the ARL model's usefulness in planning and budgeting is not seriously diminished. It provides the library administration with a scientific budgeting tool by identifying alternative means of achieving an established objective and their associated costs.

\section{REFERENCES}

1. The Library Index is briefly explained in $A R L$ Statistics, 1979-80 (Washington, D.C.: ARL, 1980); a full description of the index may be found in the ARL Library Index and Quantita- tive Relationships in the ARL, a report by Kendon Stubbs for the Committee on ARL Statistics (Washington, D.C.: ARL, 1980).

2. The cost factors shown in table 2 represent the actual costs at the XYZ institution. The workload factors for library operations are calculated from Robert M. Hayes and Joseph Becker, Handbook of Data Processing for Libraries (2d ed.; Los Angeles, Calif.: Melville Publ. Co., 1974), p.118. While the work-load factors are based on a "careful review of the literature and have been compared with the actual costs in several libraries as well as with a functional analysis of the operations themselves," the cost factors pertain to the XYZ institution and are used here for illustration only. The individual library must compare these rates with those reported by its own cost-accounting system.

\section{Appendix 1: PL/I Program}

The following PL/I program is used to develop alternative solutions to achieve an established Library Index score.

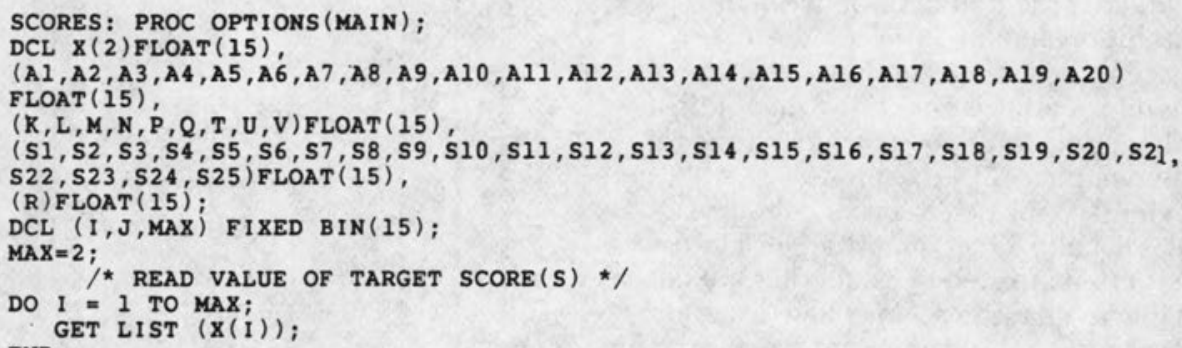

A2, $A 12=$ VOLADDED;

$A 5, A 15=$ OPEREXPEND; A6, A16= MICROFORM;

A3, A13 = CT SERIALS;

$A 11=1174396 ; A 12=57902 ; A 13=13156 ; A 14=1894321 ; A 15=625014 ;$

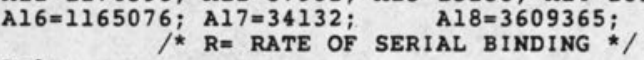


GET LIST $(\mathbf{K}, \mathrm{L}, \mathbf{M}, \mathbf{N}, \mathbf{P}, \mathbf{Q})$;

$T=((L-M) * 20.60)+(M * 23.0)$;

$\mathrm{U}=((\mathrm{L}-\mathrm{M}) * .00059)+\left(\mathrm{M}^{*} .00059\right)$

$\mathrm{V}=((\mathrm{L}-\mathrm{M}) * .00073)+\left(\mathrm{M}^{*} .00093\right)$;

$\mathrm{K}=\mathrm{K}-\mathrm{M}+\left(\mathrm{M}^{*} \mathrm{R}\right)$;

$\mathrm{L}=\mathrm{L}-\mathrm{M}+(\mathrm{M} * \mathrm{R})$;

$\mathrm{Q}=\mathrm{Q} * \mathbf{R}$;

/* COMPUTE THE SOLUTIONS FOR EACH TARGET SCORE */

DO I $=1$ TO MAX;

$/$ * SET TABLE HEADING */

PUT EDIT ('LI=', $\mathrm{X}(\mathrm{I}), \mathbf{\prime}^{\prime} \mathbf{\prime}^{\prime}$, 'DATA: $\left.^{\prime}, \mathrm{K}, \mathrm{L}, \mathrm{M}, \mathrm{N}, \mathrm{P}, \mathrm{Q}\right)$

$(\operatorname{COL}(1), A, \operatorname{col}(5), F(9,6), \operatorname{Cot}(16), A, \operatorname{Cot}(20), A, \cos (25), 6$ F (6));

PUT EDIT $\left((60)^{\prime}-\mathbf{-}^{\prime}\right)(\operatorname{COL}(1), \mathrm{A})$;

PUT EDIT ('VALUE') ( $\operatorname{COL}(30)$, Á);

PUT EDIT ( (31)' - ', 'TARGET') $(\operatorname{COL}(17), \mathrm{A}, \operatorname{COL}(53), \mathrm{A})$;

PUT EDIT ('COMPONENT', 'CURRENT', 'TARGET', 'INCREASE', 'SCORE')

$(\operatorname{Col}(1), A, \operatorname{COL}(18), A, \operatorname{COL}(29), A, \operatorname{COL}(40), A, \operatorname{COL}(53), A)$;

PUT EDIT $((60) \cdot-)(\operatorname{COL}(1), A)$;

$S 11=0$;

; * COMPUTE LIBRARY INDEX AND TEST IF TARGET SCORE IS REACHED */ DO WHILE (SII > X(I));

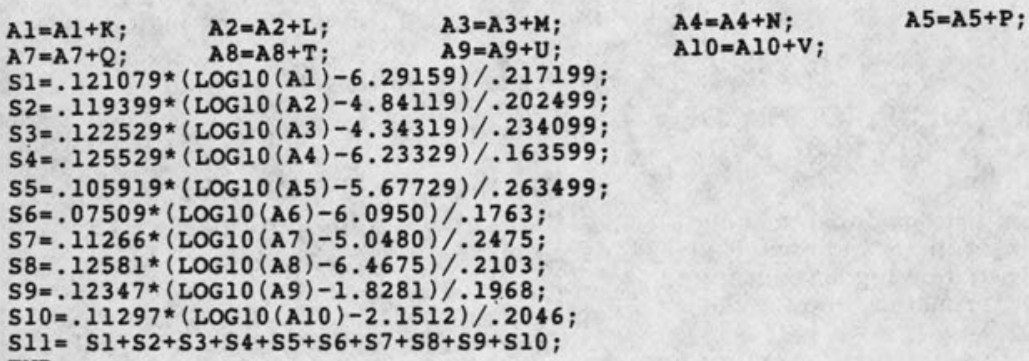
TO TARGET (IMPROVED) */

S12=A1-A11; S13=A2-A12; S14=A3-A13; S15=A4-A14; S16=A5-A15;

$\mathrm{S} 17=\mathrm{A} 6-\mathrm{A} 16$;

S18=A7-A17; S19=A8-A 18 ;

S20 =A9-A19;

$S 21=\mathrm{A} 10-\mathrm{A} 20$

$\mathrm{S} 25=\mathrm{S} 15+\mathrm{S} 16+\mathrm{S} 18+\mathrm{S} 19 ;$

* PRINT SOLUTION TABLE */

PUT EDIT ('VOLHELD', Al1, Al, S12, S1)

$(\operatorname{COL}(1), A, \operatorname{COL}(15), F(10), \operatorname{COL}(25), F(10), \operatorname{COL}(36), F(10), \operatorname{COL}(50), F(10,6))$; PUT EDIT ('VOLADDED', A12,A2, S13,S2)

$(\operatorname{Cos}(1), A, \operatorname{COL}(15), F(10), \operatorname{Col}(25), F(10), \operatorname{Col}(36), F(10), \operatorname{Col}(50), F(10,6))$; PUT EDIT ('MICROFORM', A6, A16, 517, S6)

$(\operatorname{Col}(1), A, \operatorname{Col}(15), F(10), \operatorname{COL}(25), F(10), \operatorname{Col}(36), F(10), \operatorname{CoL}(50), F(10,6))$; PUT EDIT ('CT SERIALS', Á13,A3, S14, S3)

$(\operatorname{COL}(1), A, \operatorname{Col}(15), F(10), \operatorname{COL}(25), F(10), \operatorname{Col}(36), F(10), \operatorname{Col}(50), F(10,6))$; PUT EDIT ('MATEXPEND', A14, A4, S15, S4)

$(\operatorname{Col}(1), A, \operatorname{Col}(15), F(10), \operatorname{CoL}(25), F(10), \operatorname{col}(36), F(10), \operatorname{col}(50), F(10,6))$; PUT EDIT ('BINDING', A17, A7, S18, S7)

$(\cos (1), A, \operatorname{col}(15), F(10), \cos (25), F(10), \operatorname{Col}(36), F(10), \operatorname{Col}(50), F(10,6))$; PUT EDIT ('TOTALSALARY', A18, A8, S19, S8)

$(\operatorname{col}(1), A, \operatorname{col}(15), F(10), \operatorname{col}(25), F(10), \operatorname{col}(36), F(10), \operatorname{col}(50), F(10,6))$; PUT EDIT' ('OPEREXPEND' 'Á15, A5, Sí, S5)

$(\operatorname{Col}(1), \mathrm{A}, \operatorname{Col}(15), \mathrm{F}(10), \operatorname{Col}(25), \mathrm{F}(10), \operatorname{col}(36), \mathrm{F}(10), \operatorname{col}(50), F(10,6))$; PUT EDIT' ('PROFSTAFF', Á19, A9, S20,S9)

$(\operatorname{Col}(1), A, \operatorname{col}(15), F(10), \operatorname{col}(25), F(10), \operatorname{col}(36), F(10), \operatorname{col}(50), F(10,6))$; PUT EDIT'('NONPROF', A20,A10, S21, S10)

$(\operatorname{COL}(1), A, \operatorname{CoL}(15), F(10), \operatorname{COL}(25), F(10), \operatorname{CoL}(36), F(10), \operatorname{Col}(50), F(10,6))$;

PUT EDIT ('TOTAL', SII) $(\operatorname{COL}(3), \mathbf{A}, \operatorname{COL}(50), \mathbf{F}(10,6))$;

PUT EDIT $\left((60)^{\prime}-{ }^{\prime}\right)(\operatorname{COL}(1), A)$;

PUT EDIT ('TOTAL ADDITIONAL EXPENDITURES=', S25, 'BINDING RATE=', R) $(\operatorname{COL}(1)$, $A, \operatorname{COL}(32), F(8), \operatorname{COL}(43), A, \operatorname{COL}(58), F(2,1))$;

PUT SKIP(2);

END;

END;

END SCORES; 


\section{UNIPUB \\ Supplies the Books. . . That Supply the Facts.}

\section{YEARBOOK OF INTERNATIONAL ORGANIZATIONS 1981, 19th edition}

Descriptive entries for intergovernmental organizations, international nongovernmental and nonprofit agencies, and international committees, institutes and centers offer comprehensive coverage of nearly 15,000 organizational bodies that encompass virtually every field of human endeavor.

Int'l. Chamber of Commerce

934 pp.

ORDER\# ICCM100

ISBN: 92-842-1015-1

\section{INTERNATIONAL DIRECTORY OF HIGHER EDUCATION RESEARCH INSTITUTIONS}

Features current listings of national and international institutions and organizations engaged in research on higher education in Europe, North America, and the Soviet Union.

UNESCO

$139 \mathrm{pp}$.

ORDER\# U1190

\section{CANADA YEARBOOK 1980-81}

"Biannual review of social, political, and economic developments in Canada. Includes data on energy, health, education, housing, government, demography, renewable resources, mines and minerals, communication and transportation, manufacturing, merchandising, and trade." -MARKETING NEWS

Canadian Govt. Publishing Centre ca. 1000 pp.

ORDER\# SSC169

\section{COSTS AT U.S. EDUCATIONAL INSTITUTIONS 1981/82}

Draws on annual surveys of selected US colleges and universities, listing academic calendars, tuition fees, room and board costs, and suggested monthly maintenance rates for nearly 1,000 educational institutions.

Institute of International Education

$192 \mathrm{pp}$.

ORDER \# IIE30

ISBN: $0-8720$

\section{FAO COMMODITY REVIEW AND OUTLOOK 1981-82}

Hailed by CHOICE as an Outstanding Academic Book for 1981

"This document should be in every library where users want to know about the state of the economy in less developed countries. ... This work [is] very useful for research on economic development, poverty in less developed countries, world trade, etc. . . . In short, it is an important document." - $\mathrm{CHOICE}$

Food and Agriculture Organization 1982 $128 \mathrm{pp}$.

ORDER\# F2239

$\$ 30.50$

ISBN: 92-5-101183-4

\section{WORLD GUIDE TO HIGHER EDUCATION, 1982 edition}

A worldwide, country-by-country survey of higher education systems, degrees, and qualifications. More than 130 separate country studies offer a global analysis of the problems encountered in establishing international equivalences and suggest general criteria for recognizing degrees and diplomas.

UNESCO/R. R. Bowker

ca. 300 pp.

\section{YEARBOOK OF LABOUR STATISTICS 1981, 41st edition}

This authoritative reference annual presents principal labor statistics for 180 countries and territories for the period from 1970 to 1979 .

International Labour Organization

704 pp.

ORDER\# ILO190

ISBN: 92-2-002850-6

\section{YEARBOOK OF WORLD ENERGY STATISTICS 1979}

Global in scope, this statistical yearbook furnishes data on recent developments and long-term trends affecting the status of all forms of commercial energy.

United Nations

1209 pp.

ORDER\# UN80/17/7

\section{Order with Catalog Number from}

(I)UNIPUB 1180 Avenue of the Americas

New York, NY $10036 \bullet 212-764-2791$ 